\section{Results of the prematurely terminated TEMPLE randomized controlled trial in patients with myelodysplastic syndrome: liberal versus restrictive red blood cell transfusion threshold}

To the Editor:

Red blood cell (RBC) transfusion is the cornerstone in the treatment of patients with myelodysplastic syndromes (MDS) to improve health related quality of life (HRQoL). Only very limited data is available on the optimal transfusion trigger in this setting. ${ }^{1}$ The Temple (Transfusion Effects in Myelodysplastic Patients: Limiting Exposure) Study was a multicenter, randomized, non-inferiority clinical trial that compared a restrictive ( $\mathrm{Hb}$ transfusion trigger $<4.5 \mathrm{mmoL} / \mathrm{L},<7.3 \mathrm{~g} / \mathrm{dL}$ ) with a standard (liberal) transfusion policy ( $\mathrm{Hb}$ transfusion trigger $<6.0 \mathrm{mmoL} / \mathrm{L}$, $<9.7 \mathrm{~g} / \mathrm{dL}$ ) in patients with MDS. Primary endpoint was physical fatigue, measured with the Multidimensional Fatigue Inventory (MFI). ${ }^{2}$ The study was conducted at one university and two general hospitals in the Netherlands and ethical approval was given by the University of Rotterdam's Institutional Review Board (MEC-198.887/2001/41) and all participating hospitals.

Adult patients ( $\geq 18$ years of age) diagnosed with MDS according to the French-American-British (FAB) classification ${ }^{3}$ and dependent on RBC transfusion (e.g., who had $\geq 1$ RBC transfusion recently) were eligible. Exclusion criteria were candidates for stem cell transplantation, use of growth factors (e.g., G-CSF, GM-CSF or erythropoietin), myelo-ablative chemotherapy, patients with the diagnosis Refractory Anemia with Excess Blasts in Transformation, pregnancy, patients with hemolytic anemia or congenital hemolytic disorders, severe infectious disease, and severe cardiac, pulmonal, or neurological co-morbidity at time of inclusion. Patients were not aware of the $\mathrm{Hb}$ levels during the study where physicians and nurses were aware of the group assignments. All participants had a run-in period of 3 months with a transfusion-threshold of $6 \mathrm{mmoL} / \mathrm{L}(9.7 \mathrm{~g} / \mathrm{dL})$ followed by 12 months follow up after randomization. During this run-in period MDS diagnosis was confirmed by an independent reference committee. After 3 months patients were allocated in a 1:1 ratio to the liberal or the restrictive arm. For both groups standard 2 units of RBC were transfused. RBC transfusion was allowed if severe symptoms of anemia developed or at their physician's discretion. HRQoL scores, ${ }^{2}$ physical complications and blood values were recorded. Other outcomes were number of RBC transfused, transfusion reactions, length of hospital stay, and mortality. With a sample size of 200 patients (100 per study arm), differences of 0.4 SD in MFI physical fatigue scores were detectable $(\alpha=0.05, \beta=0.20){ }^{2}$ As a non-inferiority

doi:10.1111/trf.15708

(c) $2020 \mathrm{AABB}$ design trial, the study was not adequately powered to detect clinically relevant differences.

From July 2002 till August 200421 MDS patients consented to take part in the study (Fig. 1). During the 3 months run-in period, one patient died and one patient withdrew informed consent. After 3 months, 19 patients were randomized: 10 for the restrictive arm and 9 for the liberal arm (Table 1). No significant differences were found for patient characteristics between the 2 study groups. After randomization $\mathrm{Hb}$ levels were lower in the restrictive arm leading to $17 \%$ less transfusions of RBC units compared to the liberal group. Reasons to transfuse were similar for the restrictive group and the liberal group. No transfusion reactions were reported in both groups.

The Temple study was terminated prematurely due to the slow recruitment rate with only 21 patients in three hospitals in 2 years. Patients who were still participating when the study ended, received transfusion therapy according to the guidelines of the local hospital. After randomization 6 out of 10 patients (60\%) from the restrictive and 5 out of 9 patients (55.5\%) from the liberal arm completed or still participated when the study terminated. Reasons of study withdrawal were withdrawal of informed consent (two in the restrictive and one in the liberal arm), death (one in the restrictive and two in the liberal arm) and usage of growth factors (one patient in each arm). No significant differences were found for dizziness, headache, confusion, syncope, cerebrovascular ischemia, cardiac failure, cardiac ischemia/ infarction, palpitations, tachycardia, and development of RBC allo-antibodies. Results of the HRQoL are shown in Table 1. The main reason for termination of the study was the slow inclusion rate rather than the dropout percentage. Fear of the low $\mathrm{Hb}$ trigger in these elderly patients was the main reason not to ask patients for the study. In our higher aged population (mean 75 years) with a relatively poor prognosis, the patients' compliance to the protocol was high with a participation rate after 1.5 year of approximately $60 \%$. The restrictive RBC transfusion

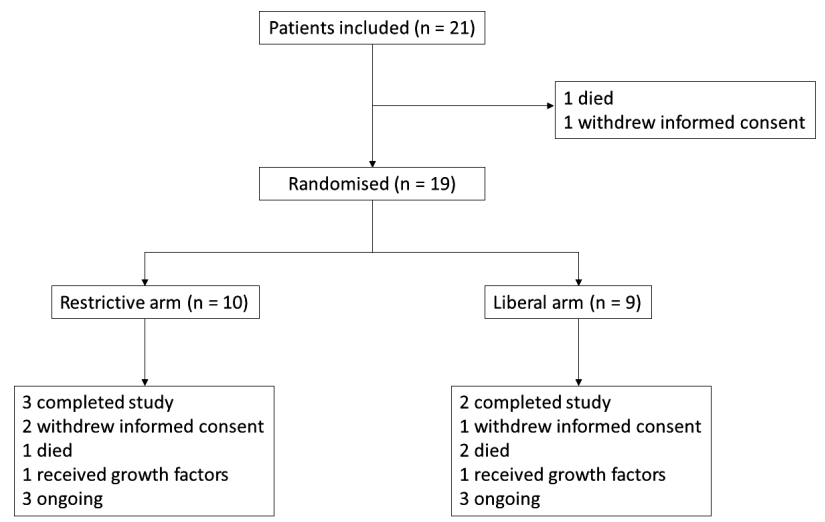

Fig. 1. CONSORT diagram of the Temple study. 
TABLE 1. Patient and RBC transfusion characteristics

\begin{tabular}{|c|c|c|}
\hline & Restrictive transfusion threshold ${ }^{\mathrm{A}}(\mathrm{N}=10)$ & Liberal transfusion threshold ${ }^{\mathrm{B}}(\mathrm{N}=9)$ \\
\hline \multicolumn{3}{|l|}{ Age (years) } \\
\hline Mean (range) & $75.7(52-91)$ & $74.9(66-80)$ \\
\hline \multicolumn{3}{|l|}{$\operatorname{Sex}(N)$} \\
\hline Male & 6 & 7 \\
\hline Female & 4 & 2 \\
\hline \multicolumn{3}{|l|}{ Diagnosis* $(\mathrm{N})$} \\
\hline Refractory anemia (RA) & 2 & 1 \\
\hline Refractory anemia with ring sideroblasts (RARS) & 4 & 1 \\
\hline Refractory Anemia with excess blasts (RAEB) & 0 & 2 \\
\hline Refractory anemia with multilineage dysplasia (RCMD) & 4 & 5 \\
\hline Chronic myelomonocytic leukemia (CMML) & 0 & 0 \\
\hline \multicolumn{3}{|l|}{ Hemoglobin value at randomization (Mean (range)) } \\
\hline $\mathrm{T}=-3$ months $(\mathrm{mmol} / \mathrm{l} / \mathrm{g} / \mathrm{dL})$ & $5.6(5.0-6.5) / 9.0(8.1-10.5)$ & $5.5(4.8-6.4) / 8.9(7.7-10.3)$ \\
\hline $\mathrm{T}=0(\mathrm{mmol} / \mathrm{l} / \mathrm{g} / \mathrm{dL})$ & $6.0(5.4-7.1) / 9.7(8.7-11.4)$ & $6.0(4.7-7.4) / 9.7(7.6-11.9)$ \\
\hline $\mathrm{T}=6$ weeks $(\mathrm{mmol} / \mathrm{l} / \mathrm{g} / \mathrm{dL})$ & $5.3(4.1-6.2) / 8.5(6.6-10.0)$ & $5.7(5.1-6.2) / 9.2(8.2-10.0)$ \\
\hline $\mathrm{T}=3$ months $(\mathrm{mmol} / \mathrm{l} / \mathrm{g} / \mathrm{dL})$ & $5.5(4.6-6.7) / 8.9(7.4-10.8)$ & $5.7(4.9-6.1) / 9.2(7.9-9.8)$ \\
\hline $\mathrm{T}=6$ months $(\mathrm{mmol} / \mathrm{l} / \mathrm{g} / \mathrm{dL})$ & $5.2(4.6-6.3) / 8.4(7.4-10.2)$ & $6.0(5.1-6.8) / 9.7(8.2-11.0)$ \\
\hline $\mathrm{T}=9$ months $(\mathrm{mmol} / \mathrm{l} / \mathrm{g} / \mathrm{dL})$ & $4.6(4.6-4.6) / 7.4(7.4-7.4)$ & $5.1(5.1-5.1) / 8.2(8.2-8.2)$ \\
\hline $\mathrm{T}=12$ months $(\mathrm{mmol} / \mathrm{l} / \mathrm{g} / \mathrm{dL})$ & $4.5(4.4-4.5) / 7.3(7.1-7.3)$ & $5.2(5.2-5.2) / 8.4(8.4-8.4)$ \\
\hline Total follow-up time (months) & $8,6(1-15)$ & $6,9(2-14)$ \\
\hline \multicolumn{3}{|l|}{ RBC characteristics $(N)$} \\
\hline Total RBC transfusions after randomization & 21 & 26 \\
\hline Total units RBC transfused & 43 & 52 \\
\hline \multicolumn{3}{|l|}{ Reasons for RBC transfusion after randomization $(\mathrm{N})$} \\
\hline Hemoglobin level & 4 & 6 \\
\hline Anemic symptoms & 10 & 7 \\
\hline Both & 7 & 8 \\
\hline Unknown & 0 & 5 \\
\hline \multicolumn{3}{|l|}{ Health related Quality of Life scores (VAS mean $\pm \mathrm{SD}$ )** } \\
\hline $\mathrm{T}=-3$ months & $55.0 \pm 16.0(\mathrm{~N}=8)$ & $69.4 \pm 14.5(\mathrm{~N}=9)$ \\
\hline $\mathrm{T}=0$ & $57.5 \pm 13.1(\mathrm{~N}=8)$ & $70.6 \pm 12.4(\mathrm{~N}=8)$ \\
\hline $\mathrm{T}=6$ weeks & $58.8 \pm 9.5(\mathrm{~N}=8)$ & $61.3 \pm 16.6(\mathrm{~N}=8)$ \\
\hline $\mathrm{T}=3$ months & $62.9 \pm 11.1(\mathrm{~N}=7)$ & $65.0 \pm 15.3(\mathrm{~N}=7)$ \\
\hline $\mathrm{T}=6$ months & $64.2 \pm 9.2(\mathrm{~N}=6)$ & $70.8 \pm 12.8(\mathrm{~N}=6)$ \\
\hline $\mathrm{T}=9$ months & $68.8 \pm 6.3(\mathrm{~N}=4)$ & $73.0 \pm 10.4(\mathrm{~N}=5)$ \\
\hline $\mathrm{T}=12$ months & $58.3 \pm 20.2(\mathrm{~N}=3)$ & $73.8 \pm 11.1(\mathrm{~N}=4)$ \\
\hline \multicolumn{3}{|l|}{ Physical Fatigue scores (Mean \pm SD) ${ }^{* * *}$} \\
\hline$T=-3$ months & $13.8 \pm 3.3(\mathrm{~N}=8)$ & $13.0 \pm 4.2(\mathrm{~N}=7)$ \\
\hline $\mathrm{T}=0$ & $12.1 \pm 5.4 \mathrm{~N}=8)$ & $10.3 \pm 4.4(\mathrm{~N}=7)$ \\
\hline $\mathrm{T}=6$ weeks & $12.1 \pm 4.6(\mathrm{~N}=8)$ & $12.6 \pm 6.3(\mathrm{~N}=8)$ \\
\hline $\mathrm{T}=3$ months & $11.7 \pm 5.7(\mathrm{~N}=6)$ & $10.3 \pm 5.2(\mathrm{~N}=7)$ \\
\hline $\mathrm{T}=6$ months & $11.5 \pm 3.0(\mathrm{~N}=6)$ & $10.7 \pm 4.3(\mathrm{~N}=6)$ \\
\hline $\mathrm{T}=9$ months & $12.3 \pm 2.5(\mathrm{~N}=4)$ & $8.4 \pm 2.6(\mathrm{~N}=5)$ \\
\hline $\mathrm{T}=12$ months & $11.3 \pm 4.9(\mathrm{~N}=3)$ & $9.0 \pm 2.9(\mathrm{~N}=4)$ \\
\hline
\end{tabular}

policy led to a reduction of $17 \%$ in RBC transfusions without cardiac complications. Although many clinical trials involve RBC transfusion triggers in acute anemia, ${ }^{4,5}$ evidence in chronic anemia is lacking. Data of the Temple study can be helpful and used as pilot study for further clinical research for which (international) collaboration is necessary.

\section{ACKNOWLEDGMENT}

We would like to express our gratitude to Prof. Dr. D.J. van Rhenen, the late Dr. W.C.J. Hop and the late Dr. J.Ph.H.B. Sybesma for their indispensable support in the design and contribution to the Temple study.

\section{CONFLICT OF INTEREST}

The authors have no conflict of interest to declare.

\section{AUTHOR CONTRIBUTIONS}

AJGJ, MRS, and EAMB designed the research study. AJGJ, JvdB, PAWteB, and MRS performed the research. AJGJ and EAMB analyzed the data and wrote the paper. JvdB, PAWteB, and MRS included patients in the study. All authors approved the final version of the manuscript.

A.J. Gerard Jansen, ${ }^{1,2}$ e-mail:a.j.g.jansen@erasmusmc.nl Joan van den Bosch, ${ }^{3}$ 


\section{Peter A.W. te Boekhorst, ${ }^{2}$ Martin R. Schipperus, ${ }^{4}$ Erik A.M. Beckers, ${ }^{1,5}$ \\ ${ }^{1}$ Sanquin Blood Bank South West Region, Rotterdam, The Netherlands \\ ${ }^{2}$ Department of Hematology, Erasmus Medical Centre, Rotterdam, The Netherlands \\ ${ }^{3}$ Department of Oncology, Albert Schweitzer Hospital, Dordrecht, The Netherlands \\ ${ }^{4}$ Department of Hematology, Leyenburg Hospital, The Hague, The Netherlands \\ ${ }^{5}$ Department of Hematology, Maastricht University Medical Centre, Maastricht, The Netherlands}

\section{REFERENCES}

1. Estcourt LJ, Malouf R, Trivella M, et al. Restrictive versus liberal red blood cell transfusion strategies for people with haematological malignancies treated with intensive chemotherapy or radiotherapy, or both, with or without haematopoietic stem cell support. Cochrane Database Syst Rev 2017;1: CD011305.

2. Jansen AJG, Essink-Bot ML, Beckers EAM, et al. Quality of life measurement in patients with transfusiondependent myelodysplastic syndromes. Br J Haematol 2013; 121:270-4.

3. Bennett JM, Catovsky D, Daniel MT, et al. Proposals for the classification of the myelodysplastic syndromes. Br J Haematol 1982;51:189-99.

4. Møller A, Nielsen HB, Wetterslev J, et al. Low vs high hemoglobin trigger for transfusion in vascular surgery: a randomized clinical feasibility trial. Blood 2019;133: 2639-50.

5. Prick BW, Jansen AJG, Steegers EAP, et al. Transfusion policy after severe postpartum haemorrhage: a randomised noninferiority trial. BJOG 2014;121:1005-14.

\section{INTERCEPT pathogen-reduced platelets are not associated with higher rates of alloimmunization with (or without) clinical refractoriness in published studies}

Reduced count increments (CIs) after platelet concentrate (PC) transfusion are most commonly caused by the patients' underlying condition, including fever, sepsis, hemorrhage, splenomegaly, and medications. Pathogen-reduced platelet concentrates (PR-PCs) effectively prevent and/or treat clinically-significant hemorrhage but may result in lower CIs than equivalent doses of conventional platelets and therefore incidently meet the definition of clinical refractoriness (commonly defined as two consecutive corrected count increments [CCIs] of $\leq 5,000$ when transfusing fresh, $\mathrm{ABO}$ matched PC). Infanti et al. show that in routine use,
61.6-77.6\% (mean 75.8\%) of conventional PC and 58.2-75.2\% (mean 64.6\%) of amotosalen/UVA treated PR-PC (INTERCEPT Blood System, Cerus Corp.) achieved CCI's $\geq 5,000$ in various patient populations. ${ }^{1}$ These data imply that by chance alone, $\left([1.0-0.758]^{2}=0.059\right) 5.9 \%$ of consecutive conventional and $\left([1.0-0.646]^{2}=0.125\right) 12.5 \%$ of consecutive INTERCEPT PC transfusions will meet the definition of clinical refractoriness. Alloimmunization to HLA class I or platelet specific antigens (e.g., PLA1) is a relatively infrequent cause but may be associated with life-threatening resistance to PC therapy and an increased risk of hemorrhagic death. The question remains whether INTERCEPT PCs, the only approved PR technology for platelets in the US, are associated with increased alloimmunization as a cause of refractoriness?

The answer is not fully known, however a general failure to adequately differentiate between available PR technologies, as well as two recent Cochrane Library metaanalyses serve to obfuscate the issue. ${ }^{2}$ In 2013, Butler et al. ${ }^{3}$ published a meta-analysis of four randomized controlled studies that included 496 INTERCEPT PC and 509 conventional PC-treated patients, and showed no significant difference in the incidence of platelet refractoriness with alloimmunization (Risk ratio 1.53, 95\% confidence interval [CI] 0.80, 2.95). Subsequently Estcourt et al. included the IPTAS study, referencing two abstracts as a source of data. ${ }^{2}$ A strong association between INTERCEPT PC and refractoriness with alloimmunization was concluded, rendering the overall risk in favor of conventional PC. Surprisingly, neither the quoted abstracts, the initial IPTAS study report, ${ }^{4}$ nor a subsequent analysis of alloimmunization in IPTAS by Norris et al., ${ }^{5}$ actually presented the number of patients shown to have both clinical refractoriness and alloimmunization. Importantly, Norris et al. state that there was a three-fold reduction that did not reach statistical significance, in high strength HLA class I alloimmunization in patients treated with INTERCEPT PC versus conventional PC. ${ }^{5}$ Data suggest that high strength HLA class I antibodies are associated with platelet refractoriness, while mid- to low-strength antibodies are not. ${ }^{6}$

With these uncertainties, we reviewed the primary data relating to alloimmunization in the IPTAS study. Rebulla et al. ${ }^{4}$ reported clinical refractoriness in 15/109 (13.8\%) INTERCEPT PC and 5/107 (4.7\%) Control PC recipients, incidences remarkably similar to that predicted by chance alone in the recently published Basel experience $(12.5 \%$ and $5.9 \%$, respectively). ${ }^{1}$ Of the 20 clinical refractory patients (Test or Control), ${ }^{4}$ HLA antibody data were missing for four patients due to lack of sample availability, and two Control and five INTERCEPT PC patients had detectable HLA class I antibodies at baseline (low-medium strength, normalized

doi:10.1111/trf.15722

(c) $2020 \mathrm{AABB}$ 